\title{
Shaut Al-'Arabiyah
}

P-ISSN : 2354-564X; E-ISSN : 2550-0317

Vol. 9 No. 1, Juni 2021

DOI : $10.24252 /$ saa.v 9 i1 1.20830

\section{العلاقة بين القدرة على قراءة القرآن بالقدرة على مهارة القراءة}

\author{
Ahmad Fadhel Syakir Hidayat ${ }^{1}$, Faradilla Zulvanni Anggraini ${ }^{2}$ \\ ${ }^{1}$ Institut Agama Islam Negeri Samarinda \\ E-mail: ${ }^{1}$ syakirhidayat887@gmail.com, ${ }^{2}$ faradillanggraini98@gmail.com
}

$$
\begin{aligned}
& \text { المستخلص : يهدف هذا البحث إلى معرفة وجود العلاقة أو عدمها بين القدرة على قراءة القرآن والقدرة على مهارة القراءة. } \\
& \text { ويُعدّ بأن هناك العلاقة ، كما ذُكر في فرضية البحث ـ هذا البحث بحث وصفي كمي. والسكان في هذا البحث هم طلبة قسم } \\
& \text { تعليم اللغة العربية للجامعة الإسلامية الحكومية سمارندا دفعة } 2019 \text { م ، وتُؤخذ منهم العينة باستخدام رمز سلوفين (slovin). } \\
& \text { ولجمع البيانات يُستخدم الاختبار والملاحظة والمقابلة والتوثيق. } \\
& \text { ويتضح من نتائج البحث أن معلَّل نتيجة اختبار القدرة على القراءة القرآن "جيد" وهو 88. وكذلك معدَّل نتيجة اختبار }
\end{aligned}
$$

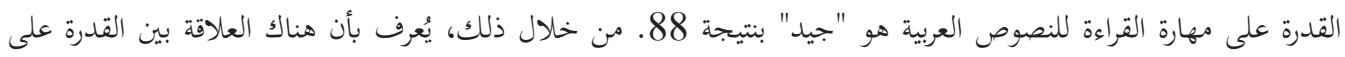

$$
\begin{aligned}
& \text { قراءة القرآن بالقدرة على مهارة القراءة عند طلبة قسم تعليم اللغة العربية للجامعة الإسلامية الحكومية سمارندا دفعة } 2019 \text { م. }
\end{aligned}
$$

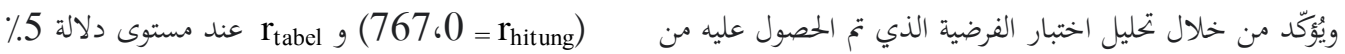

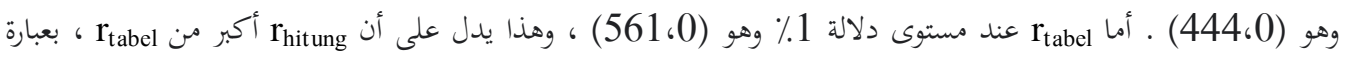

$$
\begin{aligned}
& \text { أخرى ، كلما ارتفعت القدرة على قراءة القرآن عند الطلبة ، ارتفعت القدرة على مهارة القراءة، وبالعكس. }
\end{aligned}
$$

Abstrak : Penelitian ini bertujuan untuk mengetahui ada tidaknya hubungan antara kemampuan membaca Al-Qur'an dengan kemampuan membaca. Dianggap ada hubungan, sebagaimana disebutkan dalam hipotesis penelitian. Penelitian ini merupakan penelitian deskriptif kuantitatif. Populasi dalam penelitian ini adalah mahasiswa Jurusan Pengajaran Bahasa Arab Universitas Islam Negeri Samaranda angkatan 2019, dan sampelnya diambil dengan menggunakan lambang slovin. Untuk mengumpulkan data digunakan tes, observasi, wawancara, dan dokumentasi Dari hasil penelitian terlihat bahwa rata-rata skor tes kemampuan membaca Al-Qur'an adalah "baik", yaitu 88. Demikian juga skor rata-rata tes kemampuan membaca teks bahasa Arab adalah "baik" dengan skor dari 88. Melalui hal tersebut diketahui bahwa terdapat hubungan antara kemampuan membaca Al-Qur'an dengan kemampuan keterampilan Membaca pada mahasiswa Jurusan Pengajaran Bahasa Arab Universitas Islam Negeri Samaranda Angkatan Tahun 2019 Hal ini diperkuat dengan menganalisis uji hipotesis yang diperoleh dari (rhitung $=0,767$ ) dan rtabel pada taraf signifikansi $5 \%$ yaitu $(0,444)$. Sedangkan untuk rtabel berada pada taraf signifikansi $1 \%$ yaitu $(0,561)$, hal ini menunjukkan bahwa rhitung lebih besar dari rtabel, dengan kata lain semakin tinggi kemampuan membaca Al-Qur'an siswa., semakin tinggi kemampuan membaca, dan sebaliknya.

الكلمات الئيسية : العلاقة ، القدرة على قراءة القرآن ، القدرة على مهارة القراءة 
الإسلام هو الدين المحتوي على أكبر سكان العالم ، وأكثرية سكان إندونيسيا من المسلمين. 1 القرآن

هو الكتاب المقدس ، وهو المصدر الأول والأهم من دين الإسلام ، ويكون موِّهِا ومُشِدًا للأمة الإسلامية. ومن خصائص القرآن أنه باللغة العربية ، لأن الإسلام وأنبيائه من دولة عربية التي تستخدم اللغة العربية في الحياة اليومية. "القرآن كتاب مقدس ذو أدب رفيع". "ملم يقف عند ذلك فحسب ، فالقرآن أيضًا له معنى جميل وفصاحة رائعة ونظامية القواعد اللغوية الرفيعة. واللغة العربية هي اللغة الرسمية الخامسة في الأمم المتحدة (PBB) منذ عام

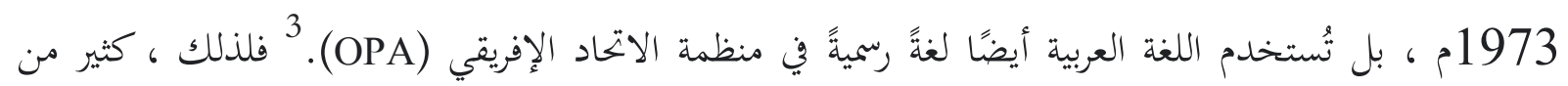
الناس من أراد أن بجعل اللغة العربية مرجعًا للدراسات من المستوى الأساسي إلى المستوى العالي. اللغة العربية والقرآن شيئان مهمان ومترابطان. ${ }^{4}$ تعلم اللغة العربية هو الأصل الأساسي في تعلم القرآن ، كما أن تعلُّم القرآن جزء مهم من تعلم اللغة العربية. اللغة العربية هي اللغة الأساسية التي استخدمها الله تعالى في

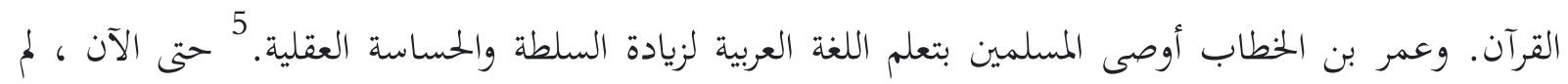
تصبح اللغة العربية في إندونيسيا شيًُا مثيرًا للاهتمام ويبدو أها شيء يصعب على الطلاب في تعلمها. في هذه

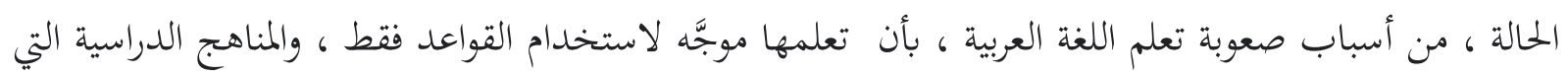
لم تصل إلى الهدف ، والمعلمون لم يفهموا تمامًا طرق التعليم وابتكارات التعليم المستجدة. 6

في ممارسة تعلم اللغة العربية ، على الأقل هناك الوجوب على الطلاب السعي في تطوير المعرفة والمهارات اللغوية ، شفويَّا كان أو تحريريًا . يتم تدريب هذه القدرة عند عملية تعليم اللغة العربية ـ في هذا الأمر ، في عالم تعليم اللغة ، تُسمَّى الكفاءة والإتقان والمهارات اللغوية بالمهارات اللغوية . ومن تلك المهارات ، مهارة الاستماع ، ومهارة الكلام ، وتُعتبران من المهارة التَّقبيلية بمعنى أها تقبل الأفكار والآراء والأخبار من الخارج . وهناك مهارة القراءة ، ومهارة الكتابة وتُعتَبران من المهارة الإنتاجية ، وهي المهارات التي توفر الأفكار والمفاهيم

${ }^{1}$ Sri Muliati, "Pengaruh Kemampuan Membaca Al-Quran Terhadap Maharah Al-Qira'ah Siswa Kelas X SMK Mumammadiyah" (UIN Sunan Kalijaga, 2016), h.1

${ }^{2}$ Mohamed Akhiruddin Ibrahim et al., "The Perception on Ulum Al-Quran Course: A Comparative Study Between Research Universities," IJAEDU-International E-Journal of Advances in Education 3, no. 7, h. 175

${ }^{3}$ Endah Suprihatin, Zaim Elmubarok, and Hasan Busri, "Pengaruh Menghafal Al Qur'an Juz 29 Terhadap Penguasaan Kosakata Dan Keterampilan Membaca Bahasa Arab Kelas X (Studi Kasus Di Mapk Al Irsyad Demak)," Lisanul' Arab: Journal of Arabic Learning and Teaching 6, no. 1 (2017), h. 39.

${ }^{4}$ Ade Destri Deviana, "Studi Korelasi Prestasi Kemampun Bahasa Arab Mahasiswa Jurusan Pendidikan Bahasa Arab Terhadap Pembelajaran Baca Al-Qur' an Ma ' Had Al-Jami' Ah Institut Agama Islam Negeri ( IAIN ) Antasari Banjarmasin Oleh Ade Destri Deviana, M . Pd . I Penelitian In” (IAIN Antasari, 2015), h. 10.

${ }^{5}$ Endah Kusumawati and Nahdliyyatul Azimah, "Analisis Tindak Tutur Ilokusi Pada Percakapan Nabi Musa AS. Dalam Surat Thaha," Shaut al Arabiyyah 8, no. 2 (December 1, 2020), h. 114.

${ }^{6}$ Hunaidu and Mahlani Sabae, "Pengaruh Penguasaan Kosakata Bahasa Arab Terhadap Kemampuan Berbahasa Arab Siswa Pondok Darul Arqam Muhammadiyah Punnia Pinrang," Jurnal Al-Maraji' 3 (2019), h. 76. 
والمعلومات للعالم الخارجي. وهذه المهارات مترابطة ، كما أن الطفل في بداية تعلم لغته الأولى يبدأ من الاستماع والكلام تمح القراءة والكتابة.

من منظور المهارات اللغوية الأساسية الأربع ، فإن أحد أهداف تعلم اللغة العربية هو تمكين الطلاب من قراءة النصوص العربية وفهمها. 8 القراءة ليست فقط نشاطًا للتعبير عن بجموعة من الأحرف أو الكلمات بشكل صحيح ، ولكنها تحتاج إلى فهم وعملية تحليل المقروء . ' القدرة على القراءة تحتوي على فهمين ـ الأول ، تحويل الرموز الكتابية إلى أصوات. ثانياً: فهم المعنى من جميع الأحوال التي تنوب عنها الرموز الكتابية والصوتية . حقيقة القدرة على القراءة تقع في الثاني ، لأن الأول أساس للثاني ، وهو القدرة على فهم المقروء . 10 بالإضافة إلى الى ذلك ، فإن هذين الأمرين يُطبَّقان في تعلم القراءة في المدارس أو المؤسسات التعليمية الأخرى. التعلم الذي يركّز في تعلم مهارة القراءة كجانب أساسي وفهم محتوى القراءة كجانب ثانٍ. يشمل الجانب الأساسي التعرف على الحروف وعناصر اللغة ، والتعرف على العلاقات مع أنماط التهجئة (pola ejaan) والأصوات وسرعة القراءة البطيئة. 11 في هذه الحالة ، تُعتبرَ الحروف الهجائية شيئًا مهمًا جادًا كأساس في تعلم اللغة العربية ، لأنه يكتوي على الجوانب ، منها الفصاحة عند قراءة كل حرف هجائي التي تُعرف من القدرة على التجويد ، فإنه يتحدد أيضًا من خلال قدرة لسان الشخص في نطق الحروف أو الجمل العربية وفقًا لخصائص وصفات ومخارج كل حرف. 12 تعلم اللغة العربية في قسم تعليم اللغة العربية (PBA) في كلية التربية (FTIK) في الجامعة الإسلامية الحكومية (IAIN) سمارندا ، يواجه الطلاب صعوبات في مهارة القراءة العربية. يبدأ ذلك من شيئ أساسي ، وهو نطق الحروف الهجائية الذي لا يناسب علم التجويد ، خاصة عند مناقشة القواعد اللغوية ، فسيؤثر على قدرة

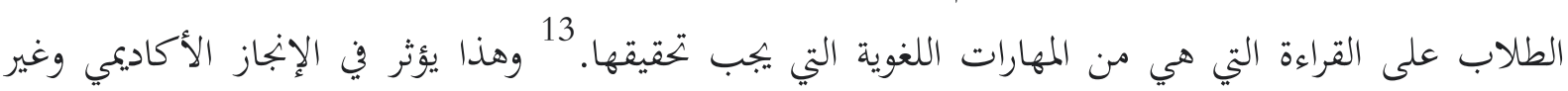
الأكاديمي على إتقان القدرة على مهارة القراءة في تحصيل المهارات اللغوية.

يُلاحَظ بأن الطلاب الذين لديهم القدرة على قراءة اللغة العربية جيدة ، فسيكون لديهم أيضًا القدرة على قراءة القرآن جيدًا. وكذلك العكس ، إذا كان الطلاب لم يكن لديهم القدرة على مهارة القراءة العربية ، فلا

${ }^{7}$ Deviana, "Studi Korelasi Prestasi Kemampun Bahasa Arab Mahasiswa Jurusan Pendidikan Bahasa Arab Terhadap Pembelajaran Baca Al-Qur' an Ma ' Had Al-Jami' Ah Institut Agama Islam Negeri ( IAIN ) Antasari Banjarmasin Oleh Ade Destri Deviana, M . Pd . I Penelitian In. (IAIN Antasari, 2015), h. 14.

${ }^{8}$ Acep Hermawan, Metodologi Pembelajaran Bahasa Arab (Bandung: PT Remaja Rosdakarya, 2014), h. 57.

${ }^{9}$ Syaiful Gala, Konsep Dan Makna Pembelajaran (Bandung: Alfabeta, 2005), h. 134.

${ }^{10}$ Khoirotun Ni'mah, "Upaya Meningkatkan Kemampuan Qiro'ah Bahasa Arab Dengan Teknik Make A Match Di Kelas V MI Pucangro Lamongan,” MIDA: Jurnal Pendidikan Dasar Islam 1, no. 1 (2018), h. 7.

${ }^{11}$ Rappe Rappe, "Kemahiran Membaca Bahasa Arab Tingkat Mutaqaddimin Serta Metode Dan Strategi Pembelajarannya," Shaut al Arabiyyah 8, no. 2 (December 1, 2020): 131, h. 8.

${ }^{12}$ Lenni Suriyanti, "Pengaruh Kemampuan Membaca AL-Quran Siswa Dan Keterampilan Mengajar Guru Terhadap Maharatul Qiraah Siswa Kelas VIII MYsN 4 Bulukamba” (UIN Alauddin, 2018), h. 5.

${ }^{13}$ Lenni Suriyanti, "Pengaruh ..., h. 9. 
يكون لديهم القدرة على قراءة القرآن. 14 بناءً على هذه المشكلة ، قام الباحثان بوَضْعها في هذا البحث بالموضوع "العلاقة بين القدرة على قراءة القرآن بالقدرة على مهارة القراءة".

والمراد بالقدرة على قراءة القرآن في هذا البحث من حيث طلق اللسان وموافق لعلم التجويد خاصة في مخارج الحروف وأما مهارة القراءة في هذا البحث هي قراءة النصوص العربية المُشكَّلة (بالحركات) من حيث تمام نطق الحروف وطلق اللسان وعلامات الترقيم .

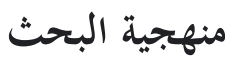

نوع هذا البحث الذي يقوم به الباحث هو بحث ميداني (field research) بالمدخل الوصفي الكمي يبحث هذا البحث العلاقة بين القدرة على قراءة القرآن والقدرة على مهارة القراءة (deskriptif-kuantitatif) العربية للطلاب المتخصصين في تعليم اللغة العربية في الجامعة الإسلامية الحكومية سمارندا ـ أما سكان البحث من طلبة قسم تعليم اللغة العربية دفعة 2019 م بأخذ العينة باستخدام رمز سلوفين (slovin) ، وعدد العينة 20 طالبا من 69 طلبًا .

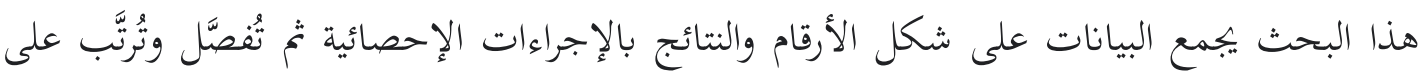
شكل بيانٍ كتابٍٍِ 15 ، الذي سيرشد إلى العلاقة بين المتغيرين (dua variabel) ، وأولمما القدرة على قراءة القرآن كمتغير حري (independent variable) وثانيهما القدرة على مهارة القراءة العربية كمتغير مقيَّد ( dependent (variable أولاً وهي بأن (Hapotesis alternatif) مهارة القراءة العربية عند طلبة قسم تعليم اللغة العربية بالجامعة الإسلامية الحكومية سمارندا ـ يرى كريسويل بأن البحث الكمي هو طريقة لاختبار هدف النظرية بدراسة العلاقة بين المتغيرين . بعض المتغيرات (creswell)

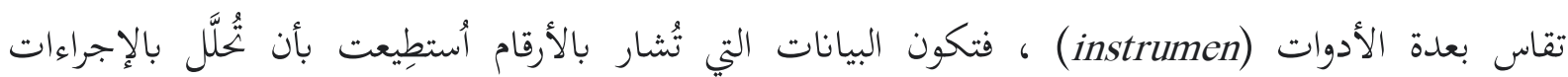
الإحصائية . 16

لنتيجة والبحث أ. أنتيجة البحث

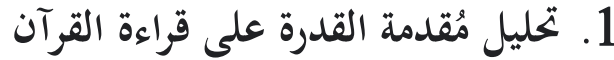

\footnotetext{
${ }^{14}$ Deviana, "Studi Korelasi Prestasi Kemampun Bahasa Arab Mahasiswa Jurusan Pendidikan Bahasa Arab Terhadap Pembelajaran Baca Al-Qur' an Ma ' Had Al-Jami' Ah Institut Agama Islam Negeri ( IAIN ) Antasari Banjarmasin Oleh Ade Destri Deviana, M . Pd . I Penelitian In. (IAIN Antasari, 2015), h. 3.

${ }^{15}$ Sugiyono, Metode Penelitian Pendidikan:(Pendekatan Kuantitatif, Kualitatif Dan $R \&$ D) (Bandung: Alfabeta, 2008), h. 15.

${ }^{16}$ John W Creswell, Research Design Pendekatan Kualitatif, Kuantitatif, Dan Mixed, Yogyakarta: Pustaka Pelajar (Yogyakarta: Pustaka Pelajar, 2010), h. 352
} 
بناءً على نتيجة اختبار القدرة على قراءة القرآن ، تبين بأن النتيجة كانت 1759 أنسائل 1700 ، بأعلى

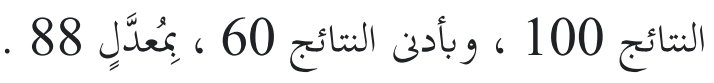

$$
\begin{aligned}
& \text { الجدول } 1
\end{aligned}
$$

جدول توزيع العدد المصنف للقدرة على قراءة القرآن عند طلبة قسم تعليم اللغة العربية IAIN سمارندا

\begin{tabular}{|c|c|c|c|}
\hline فصل الفترة & العدد & النسبة المئوية & الرتبة \\
\hline $65-56$ & 1 & $\% 5$ & ناقص \\
\hline $75-66$ & 1 & $\% 5$ & كافٍ \\
\hline $85-76$ & 8 & $\% 40$ & جيد \\
\hline $100-86$ & 10 & $\% 50$ & جيد جدا \\
\hline العدد & 20 & $\% 100$ & \\
\hline
\end{tabular}

من هذا الجدول يُعَرف أن القدرة على قراءة القرآن عند طلبة قسم تعليم اللغة العربية IAIN سمارندا

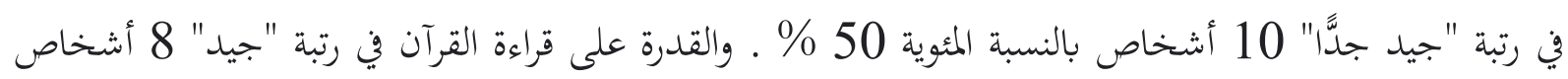

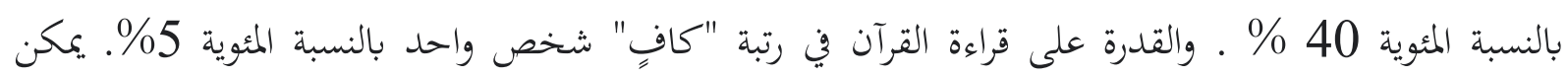

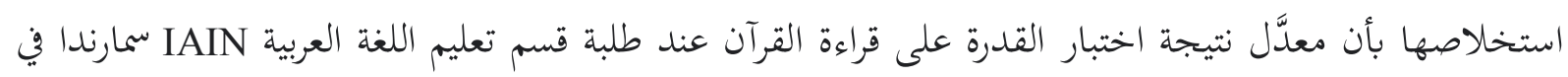
رتبة "جيد جدَّا" .

2. تحليل القدرة على مهارة القراءة العربية

بناءً على نتيجة اختبار القدرة على مهارة القراءة العربية ، تبين بأن النتيجة كانت 1758 ، بأعلى

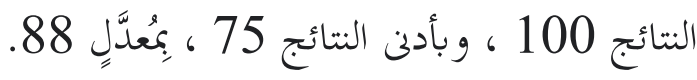

$$
\begin{aligned}
& \text { الجحدول } 2
\end{aligned}
$$

\begin{tabular}{|c|c|c|c|}
\hline فصل الفترة & العدد & النسبة المئوية & الرتبة \\
\hline $75-66$ & 1 & $\% 5$ & كافٍ \\
\hline $85-76$ & 9 & $\% 45$ & جيد \\
\hline $100-86$ & 10 & $\% 50$ & جيد جدا \\
\hline العدد & 20 & $\% 100$ & \\
\hline
\end{tabular}

جدول توزيع العدد المصنف للقدرة على مهارة القراءة عند طلبة قسم تعليم اللغة العربية IAIN سمارندا

من هذا الجدول يُعرَف أن القدرة على مهارة القراءة عند طلبة قسم تعليم اللغة العربية IAIN سمارندا في

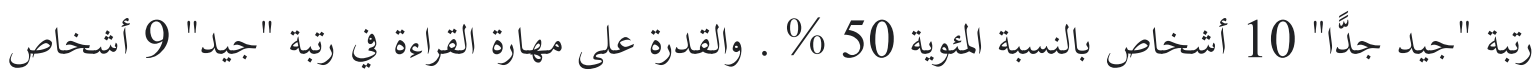

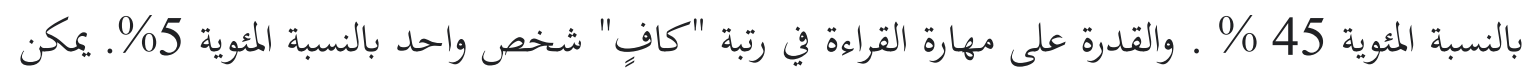


استخلاصها بأن معدَّل نتيجة اختبار القدرة على مهارة القراءة عند طلبة قسم تعليم اللغة العربية IAIN سمارندا في رتبة "جيد جدَّا" .

3.

\section{أ) اختبار الطبيعية (Normalitas)}

معايير اختبار الطبيعية من كل متغير تُنظرَ من نتائج جدول اللأهمية (Sig) . إذا كانت

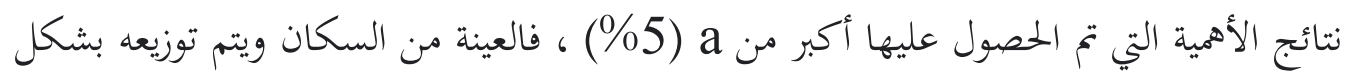

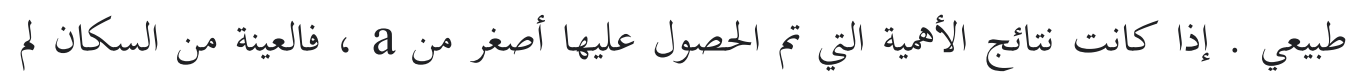

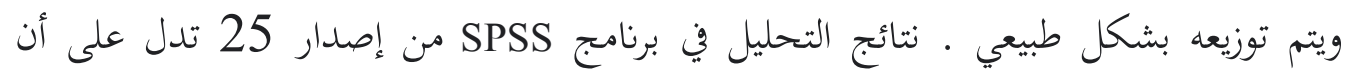

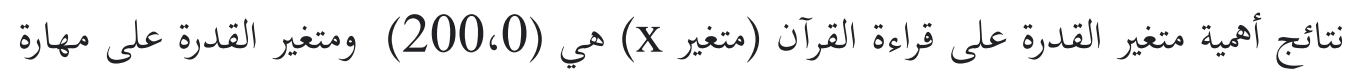

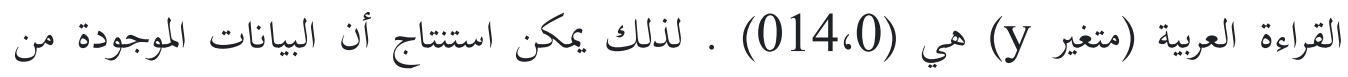

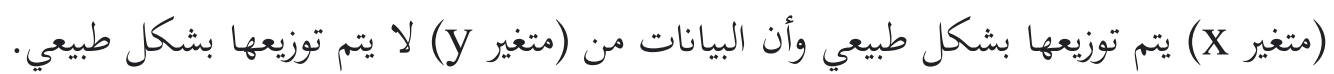

\section{(Linearitas) اختبار الخطية)}

المراد باختبار الخطية هو لمعرفة "هل المتغير الحري له تأثير خطي أم لا بالمتغير المقيَّد .

$$
\text { الجحدول }
$$

جدول أنوفا (Anova)

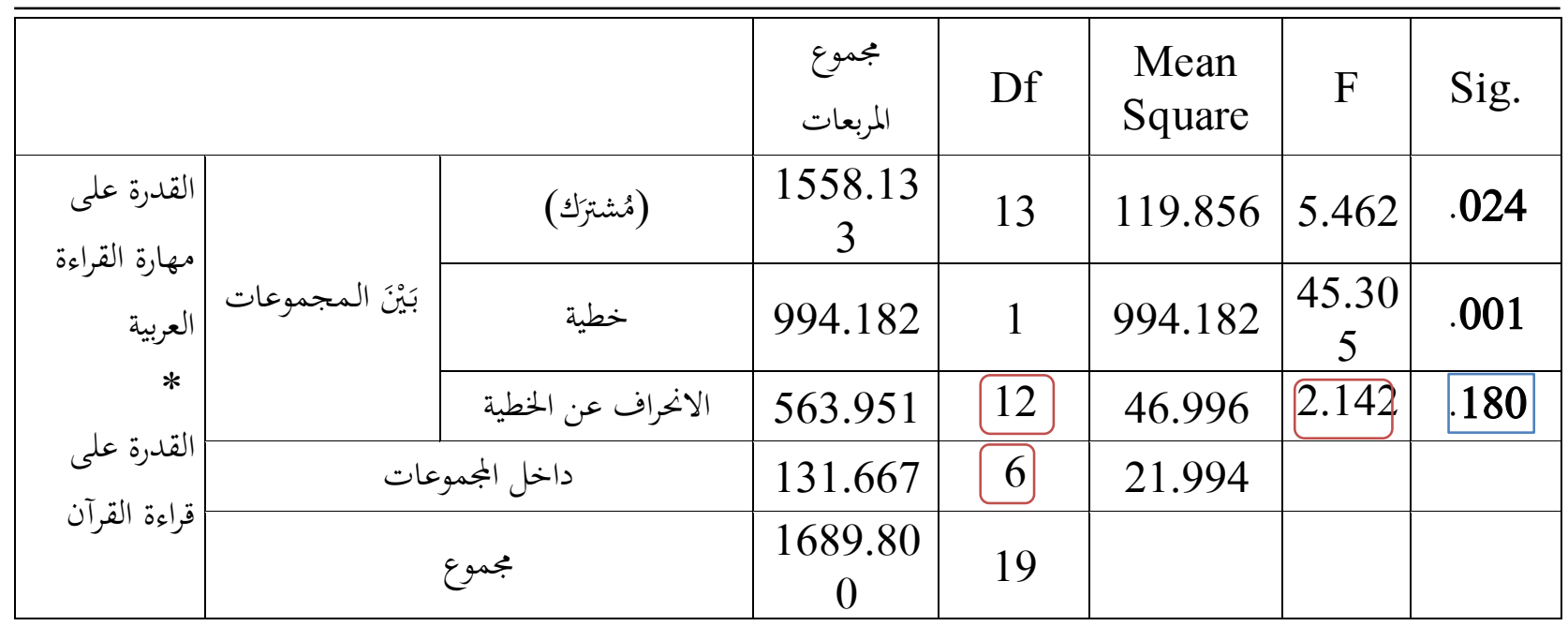

أساس اتخاذ القرار في اختبار الخطية ببرنامج SPSS من إصدار 25 يككن إجاء ذلك بطريقتين ، إما

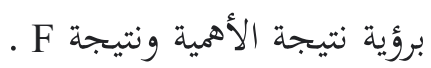


1) بناءً على نتيجة الأهمية (Sig) : يتم الحصول على نتيجة الانحراف عن الخطية Sig وهي 01860 أكبر من 0،050 ـ فيمكن استنتاجه بأن هناك العلاقة الخطية بشكل كبير بين متغير

$$
\text { القدرة على قراءة القرآن (x) بمتغير القدرة على مهارة القراءة (y) . }
$$

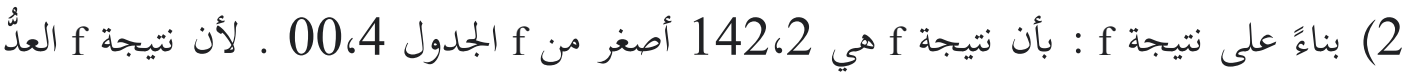

أصغر من f الجدول فيمكن استنتاجه بأن هناك العلاقة الخطية بشكل كبير بين متغير القدرة على

$$
\text { قراءة القرآن (x) بمتغير القدرة على مهارة القراءة (y) . }
$$

ج) اختبار تحليل الانحدار الخطي البسيط Analisis Regresi Linear Sederhana)

$$
\text { الجحدول } 4
$$

\begin{tabular}{|c|c|c|c|c|c|c|}
\hline & \multirow[t]{2}{*}{ Model نموذج } & \multicolumn{2}{|c|}{$\begin{array}{c}\text { Unstandardized } \\
\text { Coefficients }\end{array}$} & \multirow{2}{*}{$\begin{array}{c}\text { Standardized } \\
\text { Coefficients }\end{array}$} & \multirow[t]{2}{*}{$\mathrm{t}$} & \multirow[t]{2}{*}{ Sig. } \\
\hline & & $\mathrm{B}$ & Std. Error & & & \\
\hline \multirow[t]{2}{*}{1} & (ثابت - Constant) & 25.750 & 12.332 & & 2.088 & .051 \\
\hline & القدرة على قراءة القرآن & .707 & .139 & .767 & 5.072 & .000 \\
\hline
\end{tabular}

جدول نتيجة معامل تحليل الانحدار (koefisien analisis regresi)

\section{Coefficients $^{\mathrm{a}}$}

متغير مقيد (Dependent Variabel) : القدرة على مهارة القراءة العربية

بكسب إنتاج المعامل (coefficients) في جدول 4 ، يتم الحصول على نتيجة

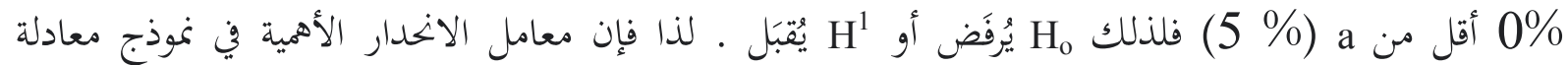

$$
\begin{aligned}
& \text { الانحدار الخطي البسيط ، يتم الحصول عليها : } \\
& X 0.707+25.750=Y
\end{aligned}
$$

5 الجدول

جدول تحليل الانحدار البسيط (analisis regresi sederhana)

\begin{tabular}{|c|c|c|c|c|}
\hline \multicolumn{5}{|c|}{ Model Summary } \\
\hline نوذج -Model & R & R Square & $\begin{array}{c}\text { Adjusted R } \\
\text { Square }\end{array}$ & $\begin{array}{c}\text { Std. Error of } \\
\text { the Estimate }\end{array}$ \\
\hline 1 & $.767^{\mathrm{a}}$ & .588 & .565 & 6.21654 \\
\hline \multicolumn{5}{|c|}{ : ثقدرة : constant - Predictors } \\
\hline
\end{tabular}

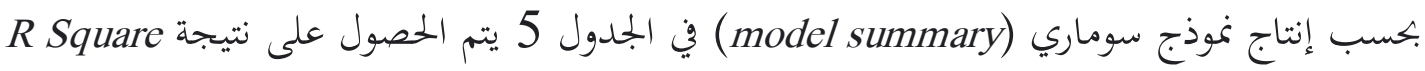

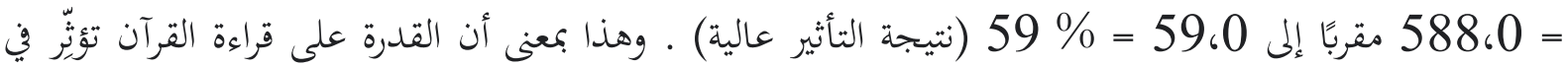

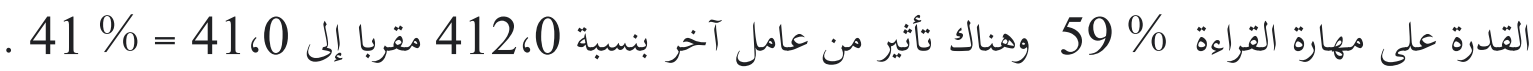


د) (Hipotesis) (اختبار الفرضية

يتم إجراء اختبار الفرضية لمعرفة وجود العلاقة أو عدمها بين متغير حري بمتغير مقيد .

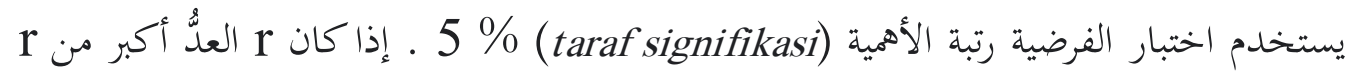

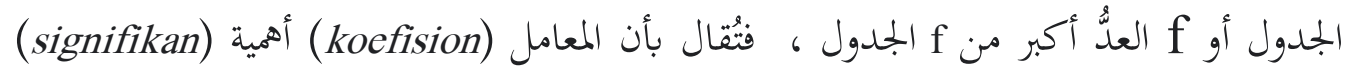
وكذلك العكس · الفرضية ثُختبَر باستخدام تحليل ارتباط لحظة المنتج ( korelasi product

$$
\begin{aligned}
& \text { (momen ببرنامج SPSS من الإصدار } 25 \text {. } \\
& \text { الجمدول } 6
\end{aligned}
$$

\begin{tabular}{|c|c|c|c|}
\hline \multicolumn{4}{|c|}{ Correlations } \\
\hline & & القدرة على قراءة & مهارة القراءة على \\
\hline \multirow{3}{*}{ القدرة على قر اءة القرآن } & $\begin{array}{c}\text { Pearson } \\
\text { Correlation }\end{array}$ & 1 & $.767^{* *}$ \\
\hline & Sig. (2-tailed) & & .000 \\
\hline & $\mathrm{N}$ & 20 & 20 \\
\hline \multirow{3}{*}{ القدرة على مهارة القر اءة } & $\begin{array}{c}\text { Pearson } \\
\text { Correlation }\end{array}$ & $.767^{* *}$ & 1 \\
\hline & Sig. (2-tailed) & .000 & \\
\hline & $\mathrm{N}$ & 20 & 20 \\
\hline
\end{tabular}

نتيجة علاقة القدرة على قراءة القرآن بالقدرة على مهارة القراءة

نتيجة التفسير من هذا الجدول تدل على أن معامل العلاقة (koefisien korelasi) للقدرة على قراءة

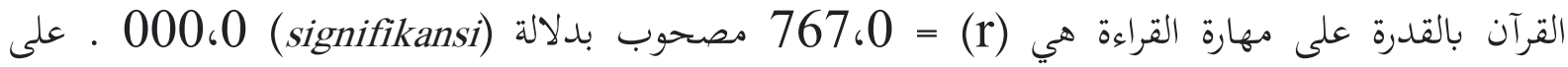
حسب معايير القرار (kriteria keputusan) في تحليل الجدول (correlation tabel) ، نتيجة في علاقة الجدول هoefisien korelasi ( (signifikan يتبين بأن مستوى الأهيمة -1 طرف معامل العلاقة تحت 0،05 في ابحاه إيجابي (positif) ـ إذن ، علاقة متغير القدرة على قراءة القرآن بمتغير القدرة على مهارة القراءة يمكن استنتاجها بأها تدل على إيبابي كبير ـ بنيجة

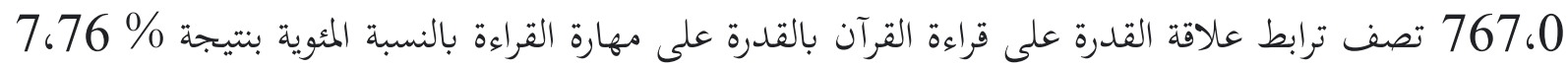
مقربًا إلى (dibulatkan) 77\% ، ولهذا يقال بوجود العلاقة الإيجابية بنفس الابتحاه . 


$$
\begin{aligned}
& \text { بناءً على نتيجة التحليل ، أن هذا البحث يدل على وجود العلاقة بين القدرة على قراءة القرآن بالقدرة } \\
& \text { علة مهارة القراءة العربية عند طلبة قسم تعليم اللغة العربية بالجامعة الإسلامية الحكومية سمارندا ـ من خلال تحليل } \\
& \text { العلاقة لحظة المنتج (product moment) من كرل بيرسون (karl pearson) يتم الحصول على }
\end{aligned}
$$

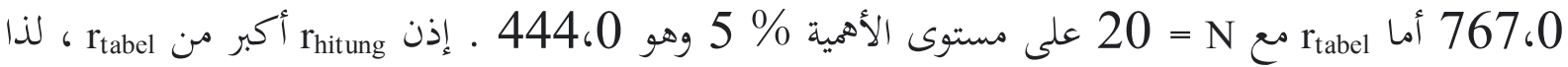

$$
\begin{aligned}
& \text { العلاقة علاقة إيجابية ذات أهمية ـ فيمكن أن يقال كلما ارتفع مستوى القدرة على قراءة القرآن لدى الطلاب ، } \\
& \text { ارتفع مستوى القدرة على مهارة القراءة العربية ـ فلهذا السبب ، الفرضية التي قُِّّمَتْ وهي "وجود العلاقة بين } \\
& \text { القدرة على قراءة القرآن بالقدرة على مهارة القراءة العربية عند طلبة قسم تعليم اللغة العربية بالجامعة الإسلامية } \\
& \text { الحكومية سمارندا " تُقبَّل حقيقتها . } \\
& \text { خلاصة البحث }
\end{aligned}
$$$$
\text { والدليل على ذلك يثبت بتحليل اختبار الفرضية الذي حصل على }
$$

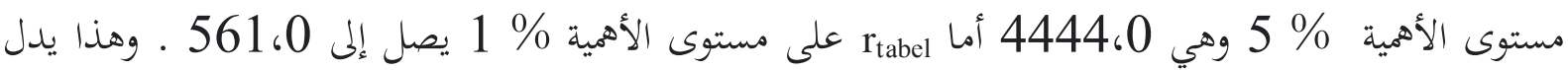

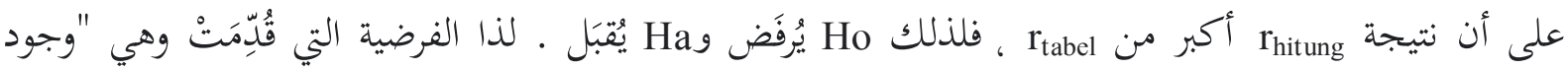$$
\text { العلاقة بين القدرة على قراءة القرآن بالقدرة على مهارة القراءة العربية عند طلبة قسم تعليم اللغة العربية بالجامعة }
$$$$
\text { الإسلامية الحلكومية سمارندا " تُقبَل حقيقتها ـ بعبارة أخرى ، كلما حسُُنَ مستوى القدرة على قراءة القرآن لدى سلى }
$$$$
\text { الطلاب ، حَسُنَ مستوى القدرة على مهارة القراءة العربية . }
$$$$
\text { فهرس المراجع }
$$

Creswell, John W. Research Design Pendekatan Kualitatif, Kuantitatif, Dan Mixed. Yogyakarta: Pustaka Pelajar. Yogyakarta: Pustaka Pelajar, 2010.

Deviana, Ade Destri. "Studi Korelasi Prestasi Kemampun Bahasa Arab Mahasiswa Jurusan Pendidikan Bahasa Arab Terhadap Pembelajaran Baca Al-Qur' an Ma 'Had Al-Jami ' Ah Institut Agama Islam Negeri ( IAIN ) Antasari Banjarmasin Oleh Ade Destri Deviana, M . Pd . I Penelitian In.” IAIN Antasari, 2015.

Gala, Syaiful. Konsep Dan Makna Pembelajaran. Bandung: Alfabeta, 2005.

Hermawan, Acep. Metodologi Pembelajaran Bahasa Arab. Bandung: PT Remaja Rosdakarya, 2014.

Hunaidu, and Mahlani Sabae. "Pengaruh Penguasaan Kosakata Bahasa Arab Terhadap Kemampuan Berbahasa Arab Siswa Pondok Darul Arqam Muhammadiyah Punnia Pinrang." Jurnal Al-Maraji' 3 (2019): 75-92.

Ibrahim, Mohamed Akhiruddin, Zulkifli Haji Mohd Yusoff, Adnan Mohamed Yusoff, Mohammad Hikmat Shaker, Shahirah Sulaiman, Ahmad Shahir Mohd Shah, and Nur Sakina Razli. "The Perception on Ulum Al-Quran Course: A Comparative Study Between Research Universities." IJAEDU- International E-Journal of Advances in Education 3, no. 7 (May 3, 2017): $174-174$. http://dergipark.gov.tr/doi/10.18768/ijaedu.315095.

Kusumawati, Endah, and Nahdliyyatul Azimah. "Analisis Tindak Tutur Ilokusi Pada Percakapan Nabi Musa AS. Dalam Surat Thaha." Shaut al Arabiyyah 8, no. 2 (December 1, 2020): 113. http://journal.uin-alauddin.ac.id/index.php/ShautulArabiyah/article/view/17559. 
Muliati, Sri. "Pengaruh Kemampuan Membaca Al-Quran Terhadap Maharah Al-Qira'ah Siswa Kelas X SMK Mumammadiyah.” UIN Sunan Kalijaga, 2016.

Ni'mah, Khoirotun. "Upaya Meningkatkan Kemampuan Qiro'ah Bahasa Arab Dengan Teknik Make A Match Di Kelas V MI Pucangro Lamongan.” MIDA: Jurnal Pendidikan Dasar Islam 1, no. 1 (2018).

Rappe, Rappe. "Kemahiran Membaca Bahasa Arab Tingkat Mutaqaddimin Serta Metode Dan Strategi Pembelajarannya." Shaut al Arabiyyah 8, no. 2 (December 1, 2020): 131. http://journal.uin-alauddin.ac.id/index.php/Shautul-Arabiyah/article/view/17786.

Sugiyono. Metode Penelitian Pendidikan:(Pendekatan Kuantitatif, Kualitatif Dan $R \& D$ ). Bandung: Alfabeta, 2008.

Suprihatin, Endah, Zaim Elmubarok, and Hasan Busri. "Pengaruh Menghafal Al Qur'an Juz 29 Terhadap Penguasaan Kosakata Dan Keterampilan Membaca Bahasa Arab Kelas X (Studi Kasus Di Mapk Al Irsyad Demak).” Lisanul' Arab: Journal of Arabic Learning and Teaching 6, no. 1 (2017): 38-43.

Suriyanti, Lenni. "Pengaruh Kemampuan Membaca AL-Quran Siswa Dan Keterampilan Mengajar Guru Terhadap Maharatul Qiraah Siswa Kelas VIII MYsN 4 Bulukamba." UIN Alauddin, 2018. 